\title{
Mental and physical health, and long-term quality of life among service members injured on deployment
}

\author{
Cameron T. McCabe ${ }^{1,2^{*}}$ (D, Jessica R. Watrous ${ }^{1,2}$, Susan L. Eskridge ${ }^{1,2}$ and Michael R. Galarneau ${ }^{1}$
}

\begin{abstract}
Background: More than 52,000 casualties have been documented in post-9/11 conflicts. Service members with extremity injuries (Els) or traumatic brain injury (TBI) may be at particular risk for long-term deficits in mental and physical health functioning compared with service members with other injuries.

Methods: The present study combined medical records with patient reports of mental health and health-related quality of life (HRQOL) for 2,537 service members injured in overseas contingency operations who participated in the Wounded Warrior Recovery Project. Combined parallel-serial mediation models were tested to examine the pathways through which injury is related to mental and physical health conditions, and long-term HRQOL.

Results: Results revealed that injury was indirectly related to long-term HRQOL via its associations with physical health complications and mental health symptoms. Relative to TBI, El was associated with a higher likelihood for a postinjury diagnosis for a musculoskeletal condition, which were related to lower levels of later posttraumatic stress disorder (PTSD) symptoms, and higher levels of physical and mental HRQOL. Similarly, El was related to a lower likelihood for a postinjury PTSD diagnosis, and lower levels of subsequent PTSD symptoms, and therefore higher physical and mental HRQOL relative to those with TBI. Despite this, the prevalence of probable PTSD among those with EI was high (35\%). Implications for intervention, rehabilitation, and future research are discussed.
\end{abstract}

Keywords: Health-related quality of life, Military, Extremity injury, Traumatic brain injury, PTSD, Musculoskeletal disorders, Cardiovascular disorders

\section{Introduction}

More than 52,000 U.S. service members have been wounded in action during overseas contingency operations following 9/11 [1]. Extremity injuries (EIs) and traumatic brain injuries (TBIs) have been described as the characteristic injuries of recent conflicts $[2,3]$, comprising a majority of injuries sustained [4]. Although acute symptoms of EI (e.g., pain, loss of function) and TBI (e.g., headache, sleep disturbances, cognitive problems) are

*Correspondence: cameron.t.mccabe.ctr@mail.mil

1 Operational Readiness Directorate, Naval Health Research Center, 140 Sylvester Road, San Diego, CA 92106, USA

Full list of author information is available at the end of the article well documented [5-8], less is known about their longterm impact for health and functioning. As the sequelae and health care needs of those injured on deployment vary based on the type, mechanism, and severity of injury, it is imperative to delineate the pathways through which combat-related injury contributes to long-term health-related quality of life (HRQOL). Further, although medical care is available to service members and veterans through Department of Defense (DoD) or Veterans Affairs facilities, many are opting to seek care through community providers [9]. Thus, it is important for both military and civilian providers to understand the longterm effects of injury in order to optimize prevention original author(s) and the source, provide a link to the Creative Commons licence, and indicate if changes were made. The images or other third party material in this article are included in the article's Creative Commons licence, unless indicated otherwise in a credit line to the material. If material is not included in the article's Creative Commons licence and your intended use is not permitted by statutory regulation or exceeds the permitted use, you will need to obtain permission directly from the copyright holder. To view a copy of this licence, visit http://creativecommons.org/licenses/by/4.0/. The Creative Commons Public Domain Dedication waiver (http://creativeco mmons.org/publicdomain/zero/1.0/) applies to the data made available in this article, unless otherwise stated in a credit line to the data. 
and intervention efforts to meet the growing needs of wounded warriors.

\section{Health-related quality of life}

HRQOL has been described as an individual's perception of their mental, physical, emotional, and social well-being at a given point in time [10]. As a concept, HRQOL incorporates aspects of one's objective medical status in concert with subjective appraisals of one's own functioning, and represents a critical patient-reported outcome [11]. Prior research among military and civilian populations suggests traumatic injuries are associated with both mental and physical health consequences, which may influence long-term HRQOL $[8,12,13]$. TBI has frequently been linked with lower perceived HRQOL among post9/11 and Gulf War era veterans [13, 14]. Similarly, EI has been associated with lower mental and physical health HRQOL [15]. In a longitudinal study of civilian patients with lower EIs, having experienced pain, as reported by the patient, was associated with worse health functioning. Over time, however, this association weakened, and was largely explained by changes in anxiety and depressive symptoms at 2 years postinjury [8].

\section{Posttraumatic stress disorder}

Posttraumatic stress disorder (PTSD) is prevalent among service members who have deployed [16]. A recent metaanalysis suggests an estimated 23\% of Operation Enduring Freedom and Operation Iraqi Freedom veterans are thought to have a PTSD diagnosis [17]. Higher rates may exist among those who sustained traumatic injuries [18-20], and while robust evidence exists linking TBI with PTSD and other mental health concerns [21, 22], mixed evidence exists with respect to the relationship between EI, PTSD, and HRQOL. In one study of U.S. service members who sustained an extremity vascular injury, Scott and colleagues [15] found high rates of pain and psychiatric disorders, and both depression and PTSD were shown to be associated with lower mental HRQOL. Characteristics of the injury themselves (e.g., limb salvage, secondary amputation), however, were not associated with long-term prognosis. In contrast, when accounting for other injuries, particularly injuries to the head and spine, Woodruff and colleagues [20] found little evidence that upper or lower EIs were correlated with mental health status or HRQOL.

\section{Physical health problems}

Although some studies contend that service members may be healthier relative to the general public (see healthy warrior effect) [23], those injured in the line of duty experience a number of physical health complications, including heightened risk for musculoskeletal disorders (MSDs)
[24] and cardiovascular disorders (CVDs) [25, 26]. MSDs are among the top reasons for medical discharge from the military [24] and for diminished readiness [27]. They also increase the likelihood of sustaining new injuries, may prolong recovery time from previous injuries [28], and have been linked to poor mental and physical health functioning and HRQOL [24].

Individuals with EI in particular, including severe EIs such as amputation or limb salvage, are at risk for both acute and chronic health complications that may require clinical intervention (e.g., pain, osteoarthritis, osteoporosis, or other musculoskeletal conditions) [29]. Moreover, individuals with lower extremity amputations are at higher risk of developing secondary health conditions (e.g., osteoarthritis, low back pain), which can contribute to lower HRQOL over time [30, 31].

Musculoskeletal conditions are also prevalent following TBI [32]. In their 2011 retrospective study of individuals hospitalized with a TBI, Brown and colleagues found nearly $80 \%$ of their sample reported musculoskeletal issues in the past 30 days, including pain, joint aches or stiffness an average of 26 years after injury, and individuals with musculoskeletal complaints reported greater bodily pain and physical health issues which impacted their daily activities relative to those without physical complaints. However, in contrast to EI, links between TBI and musculoskeletal complaints may be driven by the mechanism of injury itself which may cause trauma to other areas of the body [32].

By virtue of being exposed to a traumatic stressor, those wounded in combat may experience heightened stress response, activation of the hypothalamic-pituitary-adrenal axis, and chronic inflammation, which may damage the cardiovascular system and contribute to the development of CVDs over time [33, 34]. In their 2015 retrospective study of combat injury among U.S. service members, Stewart and colleagues demonstrated that higher injury severity was associated with greater risk of hypertension, diabetes mellitus, chronic kidney disease, and coronary artery disease [34]. Further, according to a population-based study examining blood pressure readings, as many as $13 \%$ of active duty service members may have current hypertension [35], and rates of self-reported hypertension have been shown to be higher among those diagnosed with PTSD [26] and among service members with severe EIs [29].

Individuals with a TBI may also be at heightened risk for chronic cardiovascular problems [36], however similar to links between TBI and MSD, this may be a function of secondary health complications experienced following TBI. Specifically, individuals with TBI experience sleep problems [37], inflammation and diminished immune response [38], which contribute to long-term 
cardiovascular declines. Further, Nyam and colleagues [36] showed that relative to controls, patients with TBI were at significantly higher risk for experiencing major acute cardiovascular and cerebrovascular events, cardiovascular disease, stroke, and death.

\section{Study objectives}

Adverse mental and physical health conditions are commonplace among service members with combat-related injuries $[18,20]$, and may represent mechanisms that link injury (e.g., EI, TBI) and long-term HRQOL. Although EI and TBI may be uniquely related to HRQOL outcomes, they may operate through different mechanisms and be differentially associated with secondary health complications to a greater (or lesser) extent. To date, however, this possibility has not been explored. Thus, in order to identify novel targets for prevention and intervention and optimize existing rehabilitation efforts, it is crucial to delineate potential risk factors that differentiate common injury types sustained by service members, (e.g., EI and TBI) and contribute to HRQOL deficits. Using objective medical records, in concert with data from a longitudinal examination of patient-reported outcomes of injured service members, the present study examined the pathways through which injury is related to mental and physical health conditions and long-term HRQOL. Specifically, we tested a parallel-serial mediation model whereby the associations between injury type (EI vs. TBI) and physical and mental components of HRQOL were indirect through postinjury mental (PTSD) or physical health diagnosis (MSD and CVD) and current PTSD symptomology.

We first hypothesized that relative to those with a documented TBI, service members with a documented EI (upper or lower) would be significantly less likely than those with a TBI to have a postinjury diagnosis for PTSD (H1a). In contrast, we hypothesized that individuals with an EI would be significantly more likely than those with a TBI to have a postinjury diagnosis for an MSD (H1b) and CVD (H1c). Next, because mental and physical health conditions may exacerbate existing symptoms and potentially interfere with recovery, we hypothesized that the presence of a postinjury PTSD or physical health diagnosis would be associated with higher current self-reported PTSD symptomology (H2a-H2c). Third, we examined whether postinjury PTSD (H3a, H3b) and physical health diagnoses (H3c-H3f) and current PTSD symptomology (H3g, H3h) were directly related to physical and mental HRQOL. Finally, we tested parallel-serial indirect effects of injury on physical and mental HRQOL through postinjury PTSD and physical health diagnoses and PTSD symptomology (H4a-H4f).

\section{Methods}

\section{Participants}

The study population consisted of participants in the Wounded Warrior Recovery Project (WWRP). The WWRP tracks the long-term, patient-reported outcomes of service members in the Expeditionary Medical Encounter Database (EMED), a U.S. Navy-maintained deployment health database [39]. Recruitment efforts began in November 2012, and continue on a rolling basis. Individuals who sustained a documented injury (minor to severe) while on deployment after December 2001 were contacted via email and/or postal mail, and consented to participate in a 15-year follow-up study. Each participant received a $\$ 20$ incentive for each survey battery completed. Additional details regarding WWRP methodology are available elsewhere [40]. The current study includes a subsample of all WWRP participants who enrolled in and completed relevant assessments prior to data extraction. Participants were injured between December 2001 and August 2017, and completed a WWRP assessment between September 2018 and April 2020. Overall, 3,909 participants completed an assessment during this period, We excluded 1,170 participants who either (a) did not have a documented EI or probable TBI $(\mathrm{n}=399)$ or $(\mathrm{b})$ had both a documented EI and probable TBI $(n=771)$. An additional 202 individuals were excluded from analyses due to incomplete survey or demographic data, resulting in a final study sample of 2,537 participants.

\section{Measures}

\section{Sociodemographic and injury-related information}

Descriptive and injury-related variables were gathered from EMED. EIs and TBIs were identified using the Abbreviated Injury Scale (AIS) [41]. Injury Severity Scores (ISSs) [42] were calculated from AIS codes and quantified overall trauma severity of each individual. Possible ISS values range from 0 (no injury) to 75 (fatal injury), and scores from the present study ranged from 1 to 59 . In addition, we identified participant age, service branch, military grade, and injury mechanism at the time of time of injury.

\section{Diagnostic information}

The number of medical encounters for mental and physical health conditions were calculated from inpatient and outpatient health records obtained from the Department of Defense Military Health System Data Repository using International Classification of Diseases, Ninth and Tenth Revisions, Clinical Modification (ICD-9-CM and ICD10-CM, respectively) codes. Of note, medical encounters were restricted to those that occurred after the injury but prior to responding to the WWRP questionnaire. As shown in Table 1, CVDs included hypertensive, 
Table 1 ICD-9-CM and ICD-10-CM code groups

\begin{tabular}{|c|c|c|}
\hline Code group & $I C D-9-C M$ code & $I C D-10-C M$ code \\
\hline PTSD & 30,981 & F4310-F4312 \\
\hline Musculoskeletal disorders & $\begin{array}{l}71,500-71,598,71,640-71,740,71,742-71,819,71,830- \\
71,859,71,880-71,919,71,940-72,142,7216,7218-7249 \\
7260-72,701,7295,73,399\end{array}$ & $\begin{array}{l}\text { M1280-M1389, M150, M153, M158-M1612, } \\
\text { M167-M1712, M174-M1812, M184-M19079, } \\
\text { M19211-M1991, M1993, M222X1-M222X9, } \\
\text { M2240-M2242, M23000-M23009, M23241- } \\
\text { M23249, M23261-M2352, M238X1-M24176, } \\
\text { M2440-M24443, M24451-M24476, M2450- } \\
\text { M2518, M2540-M259, M4325-M436, M438X9, } \\
\text { M450-M461, M4640-M4649, M4680-M4699, } \\
\text { M4710-M4819, M489-M546, M5489-M549, } \\
\text { M6580-M659, M6780-M6788, M7010-M7072, } \\
\text { M7500-M7582, M7610-M7672, M76821-M7712, } \\
\text { M7730-M779, M79601-M79676, M8930-M8939, } \\
\text { M898X0-M899, M948X0-M949, R262, R29898- } \\
\text { R2991 }\end{array}$ \\
\hline Cardiovascular disorders & $\begin{array}{l}4010-4149,4160-4179,4230-4293,4295-4299,4400- \\
4409,4411-4429,44,389-4439,4460-4489,4580-4599 \\
7850-7853,78,550-78,559,7859\end{array}$ & 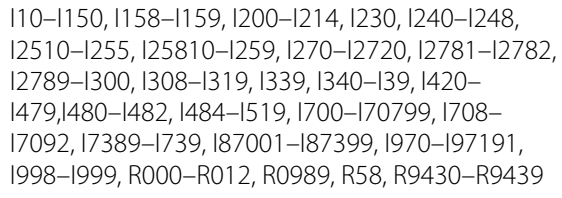 \\
\hline
\end{tabular}

ICD-9-CM = International classification of diseases, Ninth Revision, Clinical Modification; ICD-10-CM = International Classification of Diseases, Tenth Revision, Clinical Modification; PTSD = posttraumatic stress disorder

ischaemic heart disorders, heart failure, and arrhythmia, whereas codes associated with inflammatory diseases were excluded. In addition, diagnostic code groupings representing common MSDs (e.g., osteoarthritis, joint and back disorders, stress fractures) and inflammatory processes were included. Diffuse diseases of connective tissue were excluded. Finally, diagnostic codes representing PTSD were included. Participants were considered to have a given condition if they had at least one inpatient or two outpatient encounters [43, 44].

\section{Posttraumatic stress disorder}

PTSD symptom severity was assessed using the 20-item PTSD Checklist for the DSM-5 (PCL-5)[45] a widely used and validated measure of PTSD symptoms and severity over the past month. Questions refer to concerns that may arise in response to a "very stressful" life experience, and participants rated how bothered they were by each symptom using a scale of 0 (not at all) to 4 (extremely). Sample responses include "repeated, disturbing memories, thoughts, or images of a stressful experience from the past" and "feeling jumpy or easily startled." Scores were summed $(M=27.71, S D=20.15$; Cronbach's $a=0.97$ ), with higher scores representing greater symptom severity, and scores 33 or greater indicating a positive screen for PTSD [46].

\section{Quality of life}

HRQOL was assessed using the physical (PCS) and mental health component scores (MCS) calculated from the 36-item Short Form Survey (SF-36) [47]. The SF-36 has been widely used among active duty and veteran samples [48-50]. The PCS and MCS component scores are calculated using a norm-based algorithm that allows for the calculation of two, norm-based scores Functional limitations due to (1) physical health or (2) emotional problems, energy and fatigue, emotional well-being, social functioning, pain, and general health. The PCS and MCS encapsulate physical and mental HRQOL respectively, and demonstrate good internal consistency (Cronbach's as ranged from 0.84 to 0.93). In August 2019, three items were removed from the WWRP assessment as part of an ongoing DoD effort to reduce undue burden on Active Duty service members participating in survey research. Consistent with scoring guidelines [51], mean imputation was used to impute item-level scores for subscales which participants responded to at least $50 \%$ of the items. Scores ranged from 14.07 to 69.80 on the PCS and 2.73 to 70.83 on the MCS, with higher scores representing better functioning $\left(M_{P C S}=43.44, S D_{P C S}=10.19 ; M_{M C S}=40.08\right.$, $\left.S D_{M C S}=13.50\right)$.

\section{Statistical analyses}

A path model with parallel and serial mediators was run using Mplus version 8.6 [52] with weighted least square mean and variance adjusted estimation (WLSMV). A fully saturated (just-identified) model was specified to test whether injury was associated with postinjury PTSD $\left(a_{1}\right)$, MSD $\left(a_{2}\right)$, and CVD diagnoses $\left(a_{3}\right)$, as well as selfreported PTSD symptoms $\left(a_{4}\right)$, and whether each factor 
was uniquely associated with HRQOL scores (PCS or MCS; $b_{1}-b_{6}$ ). Further, this model specified additional indirect pathways, where injury was related to PCS and MCS scores through postinjury PTSD $\left(d_{1}\right), \operatorname{MSD}\left(d_{2}\right)$, and CVD encounters $\left(d_{3}\right)$, and their impact on self-reported PTSD symptoms $\left(b_{7}, b_{8}\right)$. Adjusted indirect effects for dichotomous mediators were calculated using methods described in Stride and colleagues (2015) model 4c [53]. Bias-corrected bootstrapping with resampling was used to generate $95 \%$ confidence intervals for all direct and indirect effects. Confidence intervals that do not contain a value of zero are considered statistically different from zero.

\section{Results}

\section{Descriptive statistics}

Descriptive information and sample characteristics are shown in Table 2 . Approximately $58 \%(n=1,465)$ of study participants had an EI, and $42 \%$ had a documented TBI $(n=1,072)$. Overall, most participants were male $(94.3 \%)$, enlisted (88.1\%), and in the Army (68.3\%) or Marine Corps (27.0\%) when they were injured, and most injuries were blast related (76.0\%). About $38 \%$ of participants screened positive for PTSD based on standardize cutoffs for the PCL-5.

\section{Indirect effects PTSD diagnoses}

Hypothesis H1a was supported. Relative to service members with a TBI, those with an EI were significantly less likely than those with TBI to have a documented postinjury PTSD diagnosis $(b=-0.24, p<0.001)$. In addition, postinjury PTSD diagnosis was associated with significantly higher (better) PCS scores when controlling for postinjury physical health diagnoses, self-reported mental health symptoms, and study covariates $(b=1.15$, $p=0.01)(\mathrm{H} 3 \mathrm{a})$. A significant indirect effect was observed where injury type was related to PCS through postinjury PTSD diagnosis $(a b=-0.06,95 \%$ bias-corrected confidence interval [BCCI] $[-0.09 ;-0.03])$. In contrast, postinjury PTSD diagnosis was related to significantly lower MCS scores $(b=-1.14, p<0.01)(\mathrm{H} 3 \mathrm{~b})$, and the association between injury and MCS scores was indirect through postinjury PTSD diagnosis $(a b=0.07,95 \%$ BCCI: [0.04; $0.10])$.

\section{Physical health diagnoses}

Relative to service members with a TBI, those with an EI were significantly more likely to have a documented MSD diagnosis $(b=0.32, p<0.001)$, supporting hypothesis H1b. Further, MSD diagnoses were associated with significantly lower (worse) PCS scores $(b=-3.39$, $p<0.001)(\mathrm{H} 3 \mathrm{c})$. In contrast, postinjury MSD diagnosis was related to significantly higher (better) MCS scores $(b=1.53, p<0.001)(\mathrm{H} 3 \mathrm{~d})$. The indirect effects of injury on PCS $(a b=-0.09,95 \%$ BCCI: [-0.12; -0.05$])$ and MCS $(a b=0.09,95 \%$ BCCI: $[0.05 ; 0.13])$ through postinjury MSD diagnosis were significantly different from zero (see Table 3).

When adjusting for postinjury PTSD and MSD diagnoses, and study covariates, service members with an EI were not significantly more likely than those with a TBI to have a documented CVD diagnosis $(b=0.00$, $p<0.99$ ), nor were postinjury CVD diagnoses significantly related to PCS scores $(b=-0.57, p=0.09)$ or MCS scores $(b=0.02, p=0.95)$. Thus, hypotheses H1c, and $\mathrm{H} 3 \mathrm{e}$ and $\mathrm{H} 3 \mathrm{f}$ were not supported. No significant indirect effects were observed for injury type on PCS or MCS through postinjury CVD diagnoses.

\section{Self-reported PTSD symptoms}

Injury type was not significantly related to level of PTSD symptoms on the WWRP assessment $(b=-1.14$, $p=0.26$ ). The presence of a postinjury PTSD diagnosis was associated with significantly higher levels of PTSD symptoms $(b=11.29, p<0.001)(\mathrm{H} 2 \mathrm{a})$, whereas postinjury MSD diagnosis was associated with significantly lower levels of PTSD symptoms $(b=-4.18, p<0.001)$ $(\mathrm{H} 2 \mathrm{~b})$. Contrary to our hypothesis $(\mathrm{H} 2 \mathrm{c})$, postinjury CVD diagnosis was not associated with self-reported PTSD symptoms $(b=-0.07, p=0.92)$.

Controlling for postinjury PTSD and physical health diagnoses and study covariates, PTSD symptoms were associated with significantly lower (worse) PCS $(b=-0.22, \quad p<0.001)(\mathrm{H} 3 g)$ and MCS scores $(b=-0.49, p<0.001)(\mathrm{H} 3 \mathrm{~h})$. As shown in Table 3, results suggest that injury type was related to both PCS and MCS through sequential associations with postinjury PTSD diagnoses and self-reported PTSD symptoms (see also Fig. 1). Specifically, relative to those with a TBI, service members with an EI had significantly higher (better) PCS and MCS scores by virtue of a lower likelihood of having a postinjury PTSD diagnosis, and therefore lower self-reported PTSD symptoms ( $\mathrm{H} 4 \mathrm{a}$ and $\mathrm{H} 4 \mathrm{~b}$ respectively).

A similar sequential indirect effect was found where injury type was related to PCS and MCS scores through postinjury MSD diagnoses and self-reported PTSD symptoms (Fig. 1). Relative to those with a TBI, service members with an EI had significantly higher (better) PCS and MCS scores by virtue of having a higher likelihood of having a postinjury MSD diagnosis and lower levels of self-reported PTSD symptoms (H4c and H4d respectively). No other direct or indirect effects were observed, thus $\mathrm{H} 4 \mathrm{e}$ and $\mathrm{H} 4 \mathrm{f}$ were not supported. 
Table 2 Demographic characteristics of study participants ${ }^{\mathrm{a}}$

\begin{tabular}{|c|c|c|c|}
\hline & Overall $(n=2,537)$ & El $(n=1,465)$ & TBI $(n=1,072)$ \\
\hline \multicolumn{4}{|l|}{ Age at first survey (years) } \\
\hline $18-24$ & $7(0.3)$ & $1(0.1)$ & $6(0.6)$ \\
\hline $25-29$ & $266(10.5)$ & $82(5.6)$ & $184(17.2)$ \\
\hline $30-39$ & $1491(58.8)$ & $850(58.0)$ & $641(59.8)$ \\
\hline $40-49$ & $567(22.3)$ & $385(26.3)$ & $182(17.0)$ \\
\hline $50+$ & $206(8.1)$ & $147(10.0)$ & $59(5.5)$ \\
\hline \multicolumn{4}{|l|}{ Sex } \\
\hline Male & $2392(94.3)$ & $1405(95.9)$ & $987(92.1)$ \\
\hline Female & $145(5.7)$ & $60(4.1)$ & $85(7.9)$ \\
\hline \multicolumn{4}{|l|}{ Race/ethnicity } \\
\hline Hispanic or Latino & $288(11.6)$ & $158(11.1)$ & $130(12.3)$ \\
\hline Non-Hispanic, White & $1916(77.3)$ & $1106(77.8)$ & $810(76.6)$ \\
\hline Black or African American & $165(6.7)$ & $93(6.5)$ & $72(6.8)$ \\
\hline Other/unspecified & $111(4.5)$ & $65(4.6)$ & $46(4.3)$ \\
\hline \multicolumn{4}{|l|}{ Marital status } \\
\hline Married & $1425(56.2)$ & $810(55.3)$ & $615(57.4)$ \\
\hline Unmarried & $1112(43.8)$ & $655(44.7)$ & $457(42.6)$ \\
\hline \multicolumn{4}{|l|}{ Military grade } \\
\hline Enlisted & $2125(88.1)$ & $1185(86.2)$ & $940(90.7)$ \\
\hline Officer & $286(11.9)$ & $190(13.8)$ & $96(9.3)$ \\
\hline \multicolumn{4}{|l|}{ Service branch } \\
\hline Air Force & $42(1.7)$ & $17(1.2)$ & $25(2.3)$ \\
\hline Army & $1733(68.3)$ & $1037(70.8)$ & $696(64.9)$ \\
\hline Marine Corps & $686(27.0)$ & $363(24.8)$ & $323(30.1)$ \\
\hline Navy & $76(3.0)$ & $48(3.3)$ & $28(2.6)$ \\
\hline \multicolumn{4}{|l|}{ Injury mechanism } \\
\hline Blast & $1928(76.0)$ & $991(67.6)$ & $937(87.4)$ \\
\hline Gunshot wound & $418(16.5)$ & $341(23.3)$ & $77(7.2)$ \\
\hline Other/unknown & $191(7.5)$ & $133(9.0)$ & $58(5.5)$ \\
\hline Injury severity score & $4.9(5.8)$ & $6.0(6.6)$ & $3.5(4.0)$ \\
\hline Time since injury (years) & $10.4(3.3)$ & $11.6(3.0)$ & $8.7(2.9)$ \\
\hline \multicolumn{4}{|l|}{ Medical encounters ${ }^{b}$} \\
\hline Cardiovascular disorders (\%) & $637(25.1)$ & $402(27.4)$ & $235(21.9)$ \\
\hline Musculoskeletal disorders (\%) & $1982(78.1)$ & $1219(83.2)$ & $763(71.2)$ \\
\hline PTSD (\%) & $839(33.1)$ & $457(31.2)$ & $382(35.6)$ \\
\hline \multicolumn{4}{|l|}{ Self-reported symptoms } \\
\hline PCL-5 positive screening (\%) & $963(38.0)$ & $507(34.6)$ & $456(42.5)$ \\
\hline PCL-5 score & $27.7(20.2)$ & $26.0(19.7)$ & $30.1(20.6)$ \\
\hline Physical component score & $43.8(10.2)$ & $43.6(10.3)$ & $44.0(10.0)$ \\
\hline Mental component score & $40.1(13.5)$ & $41.1(13.7)$ & $38.8(13.1)$ \\
\hline
\end{tabular}

$\mathrm{EI}=$ extremity injury; PCL-5 = Posttraumatic Stress Disorder Checklist for DSM-5; PTSD = posttraumatic stress disorder; TBI = traumatic brain injury

${ }^{a}$ Data exclude missing values. ${ }^{b}$ Percentage of medical encounters reflect proportion of participants with at least one inpatient or two outpatient diagnoses for a given condition

\section{Discussion}

Military service is a high-risk occupation where service members may be exposed to myriad hazards that affect health functioning. Service members who are injured may be at higher risk for development of later problems, yet the type and severity of injuries may manifest in unique sequelae over time. As the long-term needs and financial costs of care for wounded service members continue to rise $[54,55]$, it is vital to identify the pathways through which common types of injuries (e.g., EI, 
Table 3 Indirect effects of injury on HRQOL through postinjury physical and mental health mediators

\begin{tabular}{|c|c|c|c|}
\hline & IE & SE & $95 \% \mathrm{BCCl}$ \\
\hline Injury $\rightarrow$ PTSD Dx $\rightarrow$ SF-36 Physical & -0.06 & 0.02 & {$[-0.09 ;-0.03]$} \\
\hline Injury $\rightarrow$ PTSD Dx $\rightarrow$ SF-36 Mental & 0.07 & 0.02 & {$[0.04 ; 0.10]$} \\
\hline Injury $\rightarrow$ MSD Dx $\rightarrow$ SF-36 Physical & -0.09 & 0.02 & {$[-0.12 ;-0.05]$} \\
\hline Injury $\rightarrow$ MSD Dx $\rightarrow$ SF-36 Mental & 0.09 & 0.02 & {$[0.05 ; 0.13]$} \\
\hline Injury $\rightarrow$ CVD Dx $\rightarrow$ SF-36 Physical & 0.00 & 0.01 & {$[-0.02 ; 0.02]$} \\
\hline Injury $\rightarrow$ CVD Dx $\rightarrow$ SF-36 Mental & 0.00 & 0.01 & {$[-0.02 ; 0.02]$} \\
\hline Injury $\rightarrow$ PTSD (WWRP) $\rightarrow$ SF-36 Physical & 0.06 & 0.05 & {$[-0.05 ; 0.14]$} \\
\hline Injury $\rightarrow$ PTSD (WWRP) $\rightarrow$ SF-36 Mental & 0.15 & 0.12 & {$[-0.11 ; 0.32]$} \\
\hline Injury $\rightarrow$ PTSD Dx $\rightarrow$ PTSD (WWRP) $\rightarrow$ SF-36 Physical & 0.01 & 0.00 & {$[0.01 ; 0.02]$} \\
\hline Injury $\rightarrow$ PTSD Dx $\rightarrow$ PTSD (WWRP) $\rightarrow$ SF-36 Mental & 0.03 & 0.01 & {$[0.02 ; 0.05]$} \\
\hline Injury $\rightarrow$ MSD Dx $\rightarrow$ PTSD (WWRP) $\rightarrow$ SF-36 Physical & 0.02 & 0.01 & {$[0.01 ; 0.03]$} \\
\hline Injury $\rightarrow$ MSD Dx $\rightarrow$ PTSD (WWRP) $\rightarrow$ SF-36 Mental & 0.04 & 0.01 & {$[0.02 ; 0.06]$} \\
\hline Injury $\rightarrow$ CVD Dx $\rightarrow$ PTSD (WWRP) $\rightarrow$ SF-36 Physical & 0.00 & 0.00 & {$[-0.00 ; 0.00]$} \\
\hline Injury $\rightarrow$ CVD Dx $\rightarrow$ PTSD (WWRP) $\rightarrow$ SF-36 Mental & 0.00 & 0.00 & {$[-0.01 ; 0.01]$} \\
\hline
\end{tabular}

Effects in bold are significantly different from zero

$\mathrm{BCCl}=$ bias-corrected confidence interval; $\mathrm{CVD}=$ cardiovascular disorder; $\mathrm{Dx}=$ diagnosis; $\mathrm{HRQOL}=$ health-related quality of life; $\mathrm{IE}=$ indirect effect; $\mathrm{MSD}=$ musculoskeletal disorder; $\mathrm{PTSD}=$ posttraumatic stress disorder; $\mathrm{SE}=$ standard error; $\mathrm{SF}-36=36$-item Short Form Survey; WWRP $=$ Wounded Warrior Recovery Project

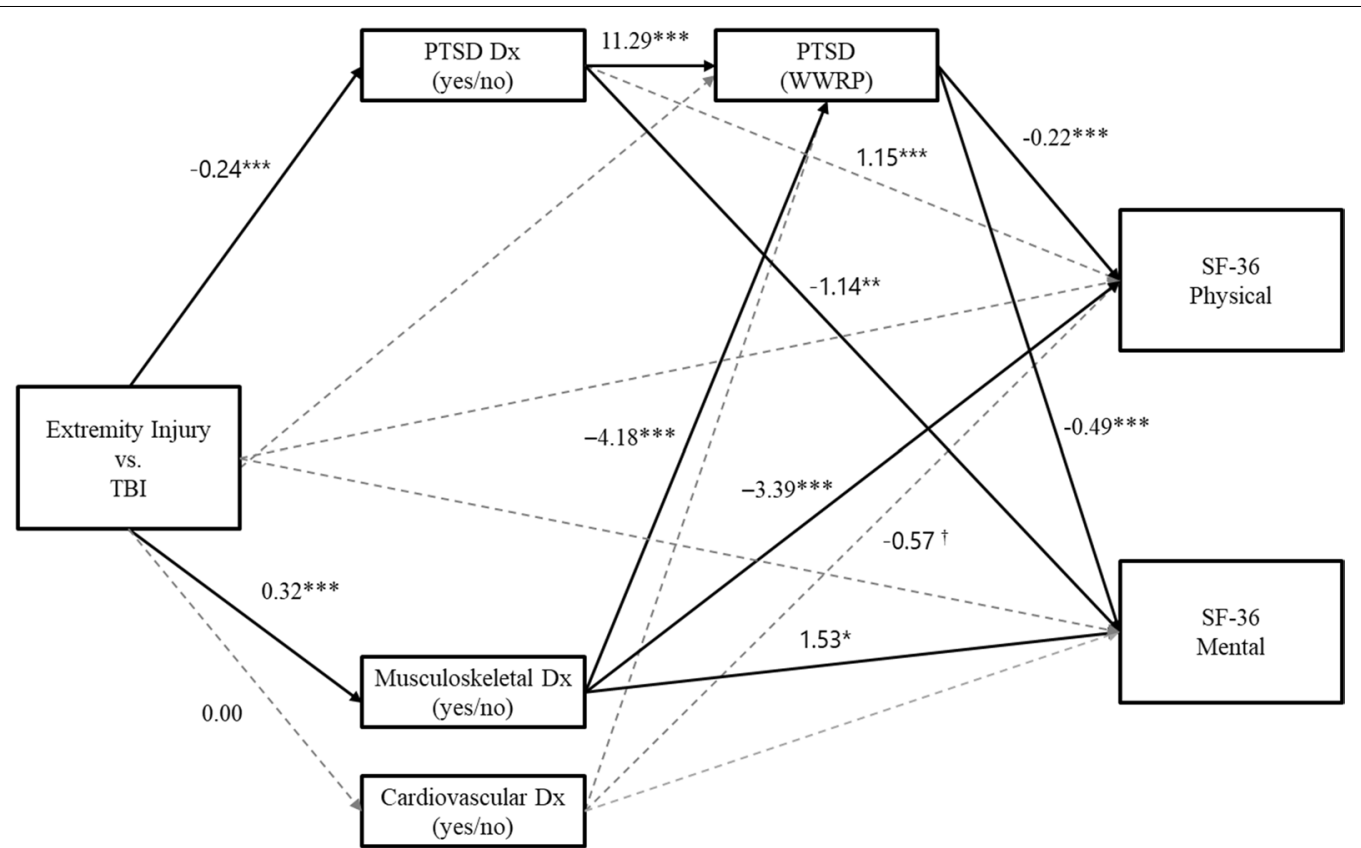

Fig. 1 Unstandardized effects of injury on health-related quality of life through postinjury physical and mental health mediators. Solid lines indicate significant indirect effect pathways; Dx= diagnosis; PTSD = posttraumatic stress disorder; SF-36=36-item Short Form Survey; TBI = traumatic brain injury; WWRP $=$ Wounded Warrior Recovery Project. ${ }^{\dagger} p<.10 ;{ }^{*} p<.05 ;{ }^{* *} p<.01 ;{ }^{* * *} p<.001$

TBI) relate to long-term health outcomes. By leveraging objective medical records with later self-reported symptoms, the present study elaborated on and extended prior health research among wounded service members, and identified multiple pathways through which injury can affect later HRQOL, demonstrating that EI and TBI were differentially related to long-term mental health symptoms and postinjury mental and physical health complications. Moreover, long-term associations between injury type and HRQOL were shown to be indirect via their association with one's level of current PTSD symptoms and likelihood of having a postinjury diagnosis for 
PTSD, and also one's likelihood of having a diagnosis for a musculoskeletal problem. These mechanisms represent critical targets of prevention and intervention for these injuries, and findings provide support for the importance of addressing both mental and physical health domains to promote health and improve the HRQOL of injured service members.

Results revealed that when adjusting for PTSD and physical health diagnoses, injury severity, and time elapsed since the injury, injury type was indirectly related to long-term HRQOL through a higher likelihood for having a postinjury musculoskeletal diagnosis, and a lower level of current PTSD symptoms. That is, despite those who sustained an EI being significantly more likely to have a musculoskeletal diagnosis than those with TBI, musculoskeletal diagnoses were associated with significantly lower PTSD symptoms, and this combination was associated with significantly higher physical and mental HRQOL. Similarly, injury type was also indirectly related to HRQOL through postinjury PTSD diagnosis and subsequent PTSD symptoms, where participants with an EI (relative to those with a TBI) reported significantly higher (better) physical and mental HRQOL through a lower likelihood of having a postinjury diagnosis for PTSD, which was associated with lower levels of PTSD symptoms.

Importantly, although we have framed these effects largely in terms of the relationship between EI and HRQOL, these effects can also be interpreted through the lens of TBI. Specifically, it is also true that TBI was associated with significantly lower likelihood of having a documented postinjury MSD diagnosis, which in turn was associated with significantly higher PTSD symptoms, and lower (worse) physical and mental HRQOL relative to those with EI. Similarly, TBI was associated with a significantly higher likelihood of having a documented postinjury PTSD diagnosis, higher subsequent PTSD symptoms, and lower (worse) physical and mental HRQOL relative to those with EI.

Results from the present study reinforce the need for optimized and integrated treatment for injured service members. As service members and veterans increase their utilization of community health resources [9], it remains critical for military and civilian providers to be aware that the mental and physical health of their patients are inextricably linked. For example, individuals with TBI in this study reported worse physical health functioning relative to those with EI despite being at lower risk for having a diagnosed physical health condition (i.e., MSD), and this effect could largely be explained through higher levels of PTSD symptoms. Further, although they did not examine mediational pathways in their epidemiological study of Australian Gulf War veterans, Kelsall and colleagues [24] demonstrated that those with MSD and comorbid PTSD or depression experience significantly lower mental and physical health functioning relative to those with MSD alone. They suggested that PTSD and/or depression may have exacerbated existing physical health symptoms or interfered with treatment effectiveness and recovery, thus resulting in worse health overall. To our knowledge, our study is one of the first studies to examine these indirect associations, and these findings emphasize the relevance of psychological health factors, in this case PTSD symptoms, for understanding pathways from injury to both mental and physical health outcomes.

We did not find evidence to suggest that injury type is indirectly related to HRQOL through cardiovascular diagnosis. That is not to say the experience of cardiovascular problems are unimportant in this process. Prior research demonstrates CVDs are a leading cause of morbidity and mortality [56], contribute to lower HRQOL [57], and may be higher among those with PTSD or depression $[43,58]$. To the extent that individuals with CVD are asymptomatic, CVD may not influence how service members perceive their HRQOL. That is, individuals who are unaware of or feel largely unencumbered by CVD-related symptoms, such as high blood pressure, may be less likely to attribute difficulties in their daily functioning to CVD, particularly if they are relatively young and otherwise healthy. This could change as conditions persist and participants age, a plausible consideration given that roughly $70 \%$ of participants were less than 39 years old at the time of the study. Another possibility is that other factors such as genetic predisposition, mental health, and certain health behaviors (e.g., sedentary lifestyle, alcohol and tobacco use, poor sleep hygiene), which contribute to heightened risk for the development of CVD [26], may further explain how CVD relates to long-term HRQOL. Nevertheless when accounting for likelihood of having a diagnosis for a postinjury PTSD or musculoskeletal condition and concurrent mental health symptoms, cardiovascular problems do not seem to drive or explain long-term links between injury type and HRQOL. Future research should examine the role of behavioral health factors in contributing to the development and maintenance of CVD, and their impact on the long-term prognosis and HRQOL of injured service members.

Although initially findings seems to contradict prior research suggesting EIs are associated with higher PTSD and other mental health symptoms $[15,18]$, this is likely a function of differences in the comparison group used across studies. As participants with EI were compared to those with TBI, this is not entirely surprising. A wealth of evidence suggests TBI is highly correlated with PTSD and other mental health concerns following injury [13, 
$21,22]$. It is important to note, however, that our study is not suggesting that EI is unrelated to PTSD symptoms or diagnosis; indeed, $35 \%$ of participants with an EI screened positive for current PTSD. However, EI is associated with lower likelihood of receiving a postinjury PTSD diagnosis relative to those with TBI. Given the comparable levels of PTSD symptoms endorsed by those with EI and TBI on the WWRP, this could indicate that PTSD is being underidentified among those with EI in the early stages following injury. Additional research is needed to examine this.

This study is not without limitations. First, although the statistical model accounted for temporality among the parameters and indirect effects, the study is correlational, and causation cannot be established. Further, the model was just-identified, restricting our ability to examine how well the model fit the data. Still, all modelled pathways were supported by prior research and theory. As previously mentioned, one potential limitation of the present study stems from our reliance on DoD medical records to determine whether participants had a documented postinjury PTSD, MSD, or CVD diagnosis. It remains possible that some visits were not accounted for if participants sought care outside the Military Health System, and it is currently unknown to what extent participants sought outside care. Another potential limitation is the lack of a noninjured comparison group. Although the findings of this study shed light on the experiences of service members with EI relative to those with TBI, these groups were mutually exclusive, and thus did not allow for the examination of comorbidity or polytrauma. Additional information could be gleaned from examining how this process unfolds relative to service members who were not injured or who sustained other injuries. Researchers examining mechanisms linking injury to long-term health outcomes should be mindful of and explicit about their respective comparison groups. Additionally, this study excluded some individuals who had both a documented EI and a probable TBI, potentially limiting its generalizability. Still, nearly $70 \%$ of the eligible WWRP sample was represented in this study, and EI and TBI remain characteristic injuries of the post-9/11 era, further supporting its overall representativeness.

\section{Conclusions}

Service members who sustain EIs and TBIs experience myriad consequences that may place them at greater or lower risk for certain health complications. Importantly, the prevalence of probable PTSD was high among those with an EI or TBI relative to veteran populations and the general public. Relative to those with TBI, however, service members with an EI were more likely to have a postinjury musculoskeletal diagnosis and less likely to have a postinjury PTSD diagnosis. Further, higher likelihood for a musculoskeletal and lower likelihood for a PTSD diagnosis were associated with lower levels of PTSD symptoms, and higher subsequent physical and mental HRQOL. Moreover, injury type was shown to be indirectly related to long-term mental and physical HRQOL through both physical (i.e., likelihood of MSD diagnosis) and mental (i.e., likelihood of PTSD diagnosis and level of PTSD symptoms) health processes. Thus, optimized treatment plans and rehabilitation efforts are needed to address secondary mental and physical health conditions, and to promote readiness, health, and overall wellness of injured service members.

\section{Abbreiviations}

AIS: Abbreiviated injury scale; BCCl: Bias-corrected confidence interval; CVD: Cardiovascular disorders; DoD: Department of defense; El: Extremity injury; EMED: Expeditionary medical encounter database; HRQOL: Health-related quality of life; ICD-9-CM: International classification of diseases, ninth revision, clinical modification; ICD-10-CM: International classification of diseases, tenth revision, clinical modification; ISS: Injury severity score; MCS: Mental health component score; MSD: Musculoskeletal disorder; PCL5: Posttraumatic stress disorder checklist for DSM-5; PCS: Physical health component score; PTSD: Posttraumatic stress disorder; SF-36: 36-Item short form survey; TBI: Traumatic brain injury; WLSMV: Weighted least square mean and variance adjusted estimation; WWRP: Wounded warrior recovery project.

\section{Acknowledgements}

We thank Amber Dougherty and Carrie Brown for reviewing and editing the manuscript, Dr. Joshua Clapp for statistical support, and Dr. Judy Dye for providing clinical support, and current and past Wounded Warrior Recovery Project team members for their work on the project.

\section{Authors' contributions}

CTM designed the study. SLE provided clinical input. JRW and MRG acquired the data. CTM analyzed the data, and all authors interpreted the data. CTM drafted the manuscript. JRW, SLE, and MRG critically revised the manuscript. All authors approved the version to be published and agree to be accountable for all aspects of the work in ensuring that questions related to the accuracy or integrity of any part of the work are appropriately investigated and resolved. All authors read and approved the final manuscript.

\section{Funding}

I am a military service member or employee of the U.S. Government. This work was prepared as part of my official duties. Title 17, U.S.C. §105 provides that copyright protection under this title is not available for any work of the U.S. Government. Title 17, U.S.C. §101 defines a U.S. Government work as work prepared by a military service member or employee of the U.S. Government as part of that person's official duties. Report No. 19-06 was supported by the U.S. Navy Bureau of Medicine and Surgery's Wounded, III, and Injured program under work unit no. 60808, and the Extremity Trauma and Amputation Center of Excellence (EACE), work unit no. N1333. The views expressed in this article are those of the authors and do not necessarily reflect the official policy or position of the Department of the Navy, Department of Defense, nor the U.S. Government. The study protocol was approved by the Naval Health Research Center Institutional Review Board in compliance with all applicable Federal regulations governing the protection of human subjects. Research data were derived from an approved Naval Health Research Center, Institutional Review Board protocol number NHRC.2009.0014.

Availability of data and materials

The datasets generated and/or analyzed during the current study are not publicly available due to personally identifiable information regulations, but 
may be made available by the corresponding author on reasonable request and approval by the Naval Health Research Center Institutional Review Board.

\section{Declarations}

\section{Ethics approval and consent to participate}

All procedures were approved by the Naval Health Research Center (NHRC) Institutional Review Board protocol number NHRC.2009.0014. All participants provided informed consent to participate.

\section{Consent for publication}

Not applicable.

\section{Competing interests}

The authors declare that they have no competing interests.

\section{Author details}

1 Operational Readiness Directorate, Naval Health Research Center, 140 Sylvester Road, San Diego, CA 92106, USA. ${ }^{2}$ Leidos, 140 Sylvester Road, San Diego, CA 92106, USA.

Received: 15 April 2021 Accepted: 31 Auqust 2021

Published online: 16 September 2021

\section{References}

1. Defense Casualty Analysis System. U.S. military casualties - OCO casualty summary by casualty type. 2017. https://dcas.dmdc.osd.mil/dcas/pages/ main.xhtml. Accessed 06 Mar 2018.

2. Dougherty AL, Mohrle CR, Galarneau MR, Woodruff SI, Dye JL, Quinn $\mathrm{KH}$. Battlefield extremity injuries in Operation Iraqi Freedom. Injury. 2009:40(7):772-7.

3. Eskridge SL, Macera CA, Galarneau MR, Holbrook TL, Woodruff SI, MacGregor AJ, et al. Injuries from combat explosions in Iraq: Injury type, location, and severity. Injury. 2012;43(10):1678-82.

4. Belmont PJ, Schoenfeld AJ, Goodman G. Epidemiology of combat wounds in operation Iraqi freedom and operation enduring freedom: orthopaedic burden of disease. J Surg Orthop Adv. 2010;19(1):2-7.

5. Dijkers MP. Quality of life after traumatic brain injury: a review of research approaches and findings. Arch Phys Med Rehabil. 2004;85(4 Suppl 2):S21-35

6. French LM, Marble SA, Greenhalgh WM. Chronic effects of TBI in a military population. In Tsao JW, editor. Traumatic brain injury: a clinician's guide to diagnosis, management, and rehabilitation. Springer International Publishing; 2015. p. 263-92.

7. Lundin A, de Boussard C, Edman G, Borg J. Symptoms and disability until 3 months after mild TBI. Brain Inj. 2009;20(8):799-806.

8. Wegener ST, Castillo RC, Haythornthwaite J, Mackenzie EJ, Bosse MJ, LEAP Study Group. Psychological distress mediates the effect of pain on function. Pain. 2011;152(6):1349-57.

9. Waitzkin H, Noble M. Caring for active duty military personnel in the civilian sector. Soc Med. 2009;4(1):56-69.

10. WHOQOL Group. (1998). The World Health Organization Quality of Life Assessment (WHOQOL): development and psychometric properties. Sco Sci Med. 1998;46(12):1569-85.

11. Moergeli $H$, Wittman L, Schnyder U. Quality of life after traumatic injury: A latent trajectory modeling approach. Psychother Psychosom. 2012;81(5):305-11.

12. Outcalt SD, Kroenke K, Krebs EE, Chumbler NR, Wu J, Yu Z, Bair MJ. Chronic pain and comorbid mental health conditions: independent associations of posttraumatic stress disorder and depression with pain, disability, and quality of life. J Behav Med. 2015;38(3):535-43.

13. Tsai J, Whealin JM, Scott JC, Harpaz-Rotem I, Pietrzak RH. Examining the relation between combat-related concussion, a novel 5-factor model of posttraumatic stress symptoms, and health-related quality of life in Iraq and Afghanistan veterans. J Clin Psychiatry. 2012;73(8):1110-8.

14. Schiehser DM, Twamley EW, Liu L, Matevosyan A, Filoteo JV, Jak AJ, Orff HJ, Hanson KL, Sorg SF, Delano-Wood L. The relationship between postconcussive symptoms and quality of life in veterans with mild to moderate traumatic brain injury. J Head Trauma Rehabil. 2015 Jul-Aug;30(4):E21-8.

15. Scott DJ, Arthurs ZM, Stannard A, Monroe HM, Clouse WD, Rasmussen TE. Patient-based outcomes and quality of life after salvageable wartime extremity vascular injury. J Vasc Surg. 2014;59(1):173-9.e1.

16. Hoge CW, Castro CA, Messer SC, McGurk D, Cotting DI, Koffman RL. Combat duty in Iraq and Afghanistan, mental health problems, and barriers to care. N Engl J Med. 2004;351(1):13-22.

17. Fulton JJ, Calhoun PS, Wagner HR, Schry AR, Hair LP, Feeling N, et al. The prevalence of posttraumatic stress disorder in Operation Enduring Freedom/Operation Iraqi Freedom (OEF/OIF) Veterans: a meta-analysis. J Anxiety Disord. 2015;31:98-107.

18. Melcer T, Walker GJ, Sechriest VF II, Galarneau MR, Konoske P, Pyo J. Shortterm physical mental health outcomes for combat amputee and nonamputee extremity injury patients. J Orthop Trauma. 2013;27(2):e31-7.

19. Walker LE, Watrous JR, Poltavskiy E, Howard JT, Janak JC, Pettey WBP, et al. Longitudinal mental health outcomes of combat-injured service members. Brain Behav. 2021. https://doi.org/10.1002/brb3.2088.

20. Woodruff SI, Galarneau MR, McCabe CT, Luu BN, Sack DI, Han PP. (2017). Body-region-specific injuries as predictors of psychosocial outcomes among those injured in combat: Results from the Wounded Warrior Recovery Project. Military Psychology. 2017;29(6):590-600.

21. Loigon A, Duellet MC, Belleville GA. Systematic review and meta-analysis on PTSD following TBI among military/veteran and civilian populations. J Head Trauma Rehabil. 2020;35(1):e21-35.

22. Polusny MA, Kehle SM, Nelson NW, Erbes CR, Arbisi PA, Thuras P. Longitudinal effects of mild traumatic brain injury and posttraumatic stress disorder comorbidity on postdeployment outcomes in National Guard soldiers deployed to Iraq. Arch Gen Psychiatry. 2011;68(1):79-89.

23. Rothberg JM, Bartone PT, Holloway HC, Marlowe DH. Life and death in the US Army: In corpore sano. JAMA. 1990:264(17):2241-4.

24. Kelsall HL, McKenzie DP, Forbes AB, Roberts MH, Urquhart DM. Sim MR Pain-related musculoskeletal disorders, psychological comorbidity, and the relationship with physical and mental well-being in Gulf War veterans. Pain. 2014;155(4):685-92.

25. Granado NS, Smith TC, Swanson GM, Harris RB, Shahar E, Smith B, et al. Newly reported hypertension after military combat deployment in a large population-based study. Hypertension. 2009;54(5):966-73.

26. Howard JT, Sosnov JA, Janak JC, Gundlapalli AV, Pettey WB, Walker LE, et al. Associations of initial injury severity and posttraumatic stress disorder diagnoses with long-term hypertension risk after combat injury. Hypertension. 2018;71(5):824-32.

27. Cameron $\mathrm{KL}$, Owens BD. The burden and management of sports-related musculoskeletal injuries and conditions within the US military. Clin Sports Med. 2014;33(4):573-89.

28. Hauret KG, Jones BH, Bullock SH, Canham-Chervak M, Canada S. Musculoskeletal injuries description of an under-recognized injury problem among military personnel. Am J Prev Med. 2010;38(Suppl 1):S61-70.

29. Melcer T, Walker J, Bhatnagar V, Richard E, Sechriest II VF, Galarneau M. A comparison of four-year health outcomes following combat amputation and limb salvage. PLoS One. 2017;12(1):e0170569.

30. Butowicz CM, Dearth $C L$, Hendershot BD. Impact of traumatic lower extremity injuries beyond acute care: movement-based considerations for resultant longer term secondary health conditions. Adv Wound Care. 2017;6(8):269-78.

31. Mazzone B, Farrokhi S, Hendershot BD, McCabe CT, Watrous JR. Prevalence of low back pain and relationship to mental health symptoms and quality of life after a deployment-related lower limb amputation. Spine. 2020;45(19):1368-75.

32. Brown S, Hawker G, Beaton D, Colantonio A. Long-term musculoskeletal complaints after traumatic brain injury. Brain Inj. 2011;25(5):453-61.

33. Rosmond R, Björntorp P. The hypothalamic-pituitary-adrenal axis activity as a predictor of cardiovascular disease, type 2 diabetes, and stroke. J Intern Med. 2000;247(2):188-97.

34. Stewart IJ, Sosnov JA, Howard JT, Orman JA, Fang R, Morrow BD, et al. Retrospective analysis of long-term outcomes after combat injury: a hidden cost of war. Circulation. 2015;132(22):2126-33.

35. Smoley BA, Smith NL, Runkle GP. Hypertension in a population of active duty service members. J Am Board Fam Med. 2008 Nov-Dec;21(6):504-11. 
36. Nyam TE, Ho C, Chio C, Lim S, Wang J, et al. Traumatic brain injury increases the risk of major adverse cardiovascular and cerebrovascular events: A 13-Year. Popul Based Stud World Neurosurg. 2019;122:e740-53.

37. Bryan CJ. Repetitive traumatic brain injury (or concussion) increases severity of sleep disturbance among deployed military personnel. Sleep. 2013;36(6):941-6.

38. Kanefsky R, Motamedi V, Mithani S, Mysliwiec V, Gill JM, Pattinson CL. Mild traumatic brain injuries with loss of consciousness are associated with increased inflammation and pain in military personnel. Psychiatry Res. 2019;279:34-9.

39. Galarneau MR, Hancock WC, Konoske P, Melcer T, Vickers RR, Walker GJ, Zouris JM. The navy-marine corps combat trauma registry. Mil Med. 2006:171(8):691-7.

40. Watrous JR, Dougherty AL, McCabe CT, Sack DI, Galarneau MR. The wounded warrior recovery project: a longitudinal examination of patientreported outcomes among deployment-injured military personnel. Mil Med. 2019;184(3-4):84-9.

41. Gennarelli TA, Wodzin E. AIS 2005: a contemporary injury scale. Injury. 2006;37(12):1083-91.

42. Baker SP, O'Neill B, Haddon W Jr, Long WB. The injury severity score: a method for describing patients with multiple injuries and evaluating emergency care. J Trauma. 1974;14(3):187-96.

43. Burg MM, Brandt C, Buta E, Schwartz J, Bathulapalli H, Dziura J, et al. Risk for incident hypertension associated with posttraumatic stress disorder in military veterans and the effect of posttraumatic stress disorder treatment. Psychosom Med. 2017;79(2):181-8.

44. Haskell SG, Ning Y, Krebs E, Goulet J, Mattocks K, Kerns R, Brandt C. Prevalence of painful musculoskeletal conditions in female and male veterans in 7 years after return from deployment in Operation Enduring Freedom/ Operation Iraqi Freedom. Clin J Pain. 2012;28(2):163-7.

45. Blevins CA, Weathers FW, Davis MT, Witte TK, Domino J. The posttraumatic stress disorder checklist for DSM-5 (PCL-5): development and initial psychometric evaluation. J Trauma Stress. 2015;28(6):489-98.

46. Weathers FW, Litz BT, Keane TM, Palmieri PA, Marx BP, Schnurr PP. The PTSD Checklist for DSM-5 (PCL-5). National Center for PTSD. 2013; Scale available from the National Center for PTSD at www.ptsd.va.gov

47. Ware JE, Sherbourne CD. The MOS 36-item short-form health survey (SF-36). I. Conceptual framework and item selection. Med Care. 1992;30(6):473-83.

48. Angkaw AC, Haller M, Pittman JO, Nunnink SE, Norman SB, Lemmer J, et al. Alcohol-related consequences mediating PTSD symptoms and mental health-related quality of life in OEF/OIF combat veterans. Mil Med 2015;180(6):670-5.

49. Jones D, Kazis L, Lee A, Rogers W, Skinner K, Cassar L. Health status assessments using the Veterans SF-12 and SF-36: Methods for evaluating outcomes in the Veterans Health Administration. J Ambul Care Manage. 2001;24(3):68-86.

50. Walter KH, Otis NP, Ray TN, Glassman LH, Michalewicz-Kragh B, Powell AL, Thomsen C. Breaking the surface: psychological outcomes of adjunctive surf therapy among service members with probable PTSD. Psychol Sport Exerc. 2019;45: 101551. https://doi.org/10.1016/j.psychsport.2019.101551.

51. Ware JE, Kosinski M, Keller SD. SF-36 physical and mental health summary scales: a user's manual. Boston, MA: Health Assessment Lab; 1994.

52. Muthén LK, Muthén BO. Mplus User's Guide. 8th ed. Los Angeles, CA: Muthén \& Muthén; 1998-2017.

53. Stride CB, Gardener S, Catley N. 'Mplus Code for Mediation, Moderation, and Moderated Mediation Models'. 2015. http://www.offbeat.group.shef. ac.uk/FIO/models_and_index.pdf. Accessed 08 Feb 2021.

54. Frayne SM, Chiu VY, labal S, Berg EA, Laungani KJ, Cronkite RC, et al. Medical care needs of returning veterans with PTSD: their other burden. J Gen Intern Med. 2011;26(1):33-9.

55. Possemato K, Wade M, Andersen J, Ouimette P. The impact of PTSD, depression, and substance use disorders on disease burden and health care utilization among OEF/OIF veterans. Psychol Trauma. 2010:2(3):218-23.

56. Johnson NB, Hayes LD, Brown K, Hoo EC, Ethier KA. CDC National Health Report: Leading causes of morbidity and mortality and associated behavioural risk and protective factors - United States, 2005-2013. MMWR Suppl. 2014;63(4):3-27.

57. Ludt S, Wensing M, Szecsenyi J, van Lieshout J, Rochon J, Freund T, et al. Predictors of health-related quality of life in patients at risk for cardiovascular disease in European primary care. PLoS One. 2011;6(12):e29334.

58. Ulmer CS, Bosworth HB, Germain A, Lindquist J, Olsen M, Brancu M, et al. Associations between sleep difficulties and risk factors for cardiovascular disease in veterans and active duty military personnel of the Iraq and Afghanistan conflicts. J Behav Med. 2015;38(3):544-55.

\section{Publisher's Note}

Springer Nature remains neutral with regard to jurisdictional claims in published maps and institutional affiliations.
Ready to submit your research? Choose BMC and benefit from:

- fast, convenient online submission

- thorough peer review by experienced researchers in your field

- rapid publication on acceptance

- support for research data, including large and complex data types

- gold Open Access which fosters wider collaboration and increased citations

- maximum visibility for your research: over $100 \mathrm{M}$ website views per year

At BMC, research is always in progress.

Learn more biomedcentral.com/submissions 